\title{
In situ construction of Ir@Pt/C nanoparticles in the cathode layer of membrane electrode assemblies with ultra-low Pt loading and high Pt exposure
}

\author{
Dai Dang ${ }^{a}$, Lei Zhang ${ }^{b}$, Xiaoyuan Zeng ${ }^{a}$, Xinlong Tian ${ }^{a}$, Chong Qu ${ }^{b}$, Haoxiong Nan ${ }^{a}$, Ting \\ Shu ${ }^{a}$, Sanying Hou ${ }^{a}$, Lijun Yang ${ }^{a}$, Jianhuang Zeng ${ }^{a}$, Shijun Liao ${ }^{a *}$ \\ a School of Chemistry and Chemical Engineering, South China University of Technology, The Key \\ Laboratory of Fuel Cell Technology of Guangdong Province \& The Key Laboratory of New Energy \\ Technology of Guangdong Universities, Guangzhou 510641, China. \\ b School of Materials Science and Engineering, Georgia Institute of Technology, Atlanta, GA \\ 30332-0245, USA.
}

\begin{abstract}
A novel membrane electrode assemblies (MEAs) with ultra-low Pt loadings and high Pt exposure in the cathode layer is prepared by spraying Ir/C catalyst ink on the membrane surface to form a substrate layer, followed by in situ pulse electrochemical deposition of a Pt shell layer on the Ir core nanoparticles in the substrate layer. It makes the Pt loadings on cathode lower to $0.044 \mathrm{mg} / \mathrm{cm}^{2}$. In our system, the MEA with our novel cathode exhibits excellent performance in a $\mathrm{H}_{2} /$ air single fuel cell, which is comparable to that of the MEA prepared with commercial $\mathrm{Pt} / \mathrm{C}$ catalyst (Johnson Matthey $40 \% \mathrm{Pt}$ ) with Pt loadings of $0.1 \mathrm{mg} / \mathrm{cm}^{2}$. The electrode with core-shell structured catalysts is characterized by X-ray diffraction, X-ray photoelectron spectroscopy, EDS line-scan, and scanning transmission electron microscopy. Based on the characterization results, it is found that the $\mathrm{Pt}$ is highly dispersed on the Ir NPs, and the electronic feature of Pt at shell layer can be tuned by

* Corresponding author, E-mail: chsjliao@scut.edu.cn, fax +86 20 87113586. (Shijun Liao).
\end{abstract}


the Ir core particle. Furthermore, the DFT calculation results also reveal the interaction between $\mathrm{Pt}$ at shell layer and Ir core. This work may provide a novel pathway to realize low $\mathrm{Pt}$ and high Pt utilization in low temperature fuel cells.

Key words: ultra-low Pt loading; core-shell structure; membrane electrode assembly; fuel cell; DFT 


\section{Introduction}

Polymer electrolyte membrane fuel cells (PEMFCs), recognized as the most promising clean power sources for automobiles, have gained significant interest due to their high energy efficiency, zero harmful emissions, and remarkable environmental neutrality [1-3]. In order to speed up their commercialization, some major obstacles have to be overcome, including a high cost of Pt catalysts, relatively sluggish oxygen reduction kinetics, and poor cell stability [4-6]. Conventional membrane electrode assemblies (MEAs) have high Pt loadings (a typical figure is $0.6-0.7 \mathrm{mg} \mathrm{Pt} \mathrm{cm}{ }^{-2}$ on both sides) to maintain acceptable chemical reaction rates and reasonable cell power outputs. Unfortunately, these high Pt loadings are not fully used, and, in fact, a large proportion of the Pt catalyst in a conventional MEA is wasted due to the following reasons: (i) active Pt nanoparticles (NPs) embedded in carbon powder remain isolated from the solid electrolyte (Nafion $\left.{ }^{\circledR}\right)$ and/or (ii) Pt catalysts may be trapped in a film of the solid electrolyte since a binder has been used to prepare the catalyst layer [4, 7]. Hence, not to be exaggerated, up to $70 \%$ of Pt catalysts may remain unexposed to the reactants.

To achieve PEMFC commercialization, Pt loadings in the electrode must be reduced substantially from the current level of a few $\mathrm{mg} \mathrm{cm}^{-2}$ to lower than $0.1 \mathrm{mg}$ $\mathrm{cm}^{-2}$. This target could only be achieved through the development of novel catalysts as well as a satisfactory nanostructured catalyst layer in the MEA [8-9]. M.Debe et al designed the advanced electrode with unique structure. The as-prepared MEA can achieve very high cell performance but Pt loading in the MEA was only $0.15 \mathrm{mg} / \mathrm{cm}^{2}$ 
for both anode and cathode [2]. Meanwhile, one workable mean to lower catalyst cost is to design core-shell (Pt shell) structured electrocatalysts [10-14]. The formation of a Pt shell could further tune its surface electronic structure by the core elements underneath and improve Pt utilization significantly [15-19]. Another approach is to deposit Pt catalysts directly on the triple-phase zone in the MEA, making Pt catalysts fully available to the reactants and ions [20-22].

A feasible strategy for creating MEAs with low Pt loading was recently proposed by our group [23]: a relatively inexpensive metal catalyst (e.g., $\mathrm{Ir} / \mathrm{C}, \mathrm{Ru} / \mathrm{C}$ ) was prepared as a base catalyst layer/electrode followed by in-situ Pt deposition via a pulse deposition method. Theoretically, the Pt atoms are fully exposed and the utilization efficiency could reach its limit. It was found that MEAs prepared by this method exhibited enhanced performance as was expected.

A few successful studies on Ir@Pt/C catalysts have been carried out in recent years for methanol oxidation and oxygen reduction reactions in acidic solutions [24-25]. Hence, as a consistent effort to prepare MEAs with low Pt loadings in our lab, in this study, we select Ir/C as the base catalyst and then deposit a layer of Pt atoms on the catalyst layer consisting of $\mathrm{Ir} / \mathrm{C}$, yielding a high-performance MEA with a core-shell Ir@Pt/C catalyst as the cathode. The enhanced performance was theoretically carried out by DFT calculations, which revealed the interaction between Pt shell and Ir core.

\section{Experimental}

\subsection{Preparation of $\mathrm{Ir} / \mathrm{C}$}


$\mathrm{Ir} / \mathrm{C}$, which was used as the core of $\operatorname{Ir} @ \mathrm{Pt} / \mathrm{C}$, was prepared using an impregnation-reduction method reported by our group recently [26]. Briefly, pre-treated XC72R carbon black was ultrasonically mixed with $\mathrm{IrCl}_{3}$ solution for 30 min to form a homogeneous ink; then the ink was allowed for evaporation at $70^{\circ} \mathrm{C}$ under magnetic stir; the dried product was finally transferred into a crucible in a tubular furnace, followed by hydrogen reduction for $1 \mathrm{~h}$ at an appropriate temperature. The nominal Ir loading in the Ir/C was general $20 \%$ by weight, and the actual content was determined by atomic absorption spectroscopy (AAS).

The effects of reduction temperature, content of Ir, and particle size of Ir NPs on the performance of final MEAs were systematically investigated, and it was found that MEA, prepared with the $\mathrm{Ir} / \mathrm{C}$ with $20 \mathrm{wt} \%$ content, reduced at $300{ }^{\circ} \mathrm{C}$, and with particle size of $4.1 \mathrm{~nm}$, exhibits the best single cell performance, thus, the above described optimal Ir/C material was used for all investigations in this paper.

\subsection{In-situ Preparation of Ir@Pt/C electrodes}

A two-stage strategy was employed to prepare Ir@Pt/C cathode electrodes, which is depicted in the Fig.1. First, a base Ir/C (20 wt\% Ir) catalyst layer was prepared using a catalyst coated membrane (CCM) method [27] and then $\mathrm{Ir} / \mathrm{C}$ was mixed with $5 \mathrm{wt} \%$ Nafion ${ }^{\circledR}$ ionomer solution (DuPont, USA) and isopropanol. After sonication for $30 \mathrm{~min}$, the homogeneous catalyst slurry was directly sprayed onto one side of a pretreated membrane $\left(\mathrm{Nafion}{ }^{\circledR} 212,50 \mu \mathrm{m}\right)$, covering an area of $5 \mathrm{~cm}^{2}$. The mass ratio of the $\operatorname{Ir} / \mathrm{C}$ to Nafion ${ }^{\circledR}$ (dry content) in the slurry was $2.2 / 1$ and the Ir loading in the base catalyst layer was $0.039 \mathrm{mg} \mathrm{cm}^{-2}$. Second, the Ir@Pt/C cathode catalyst layer 
was prepared by the deposition of a thin Pt layer on the surface of Ir NPs (which was embedded in the $\mathrm{Ir} / \mathrm{C}$ base catalyst layer) using a pulse electrodeposition (PED) approach (the set-up and procedure can be found in our recent work [23]). The deposition current density for the PED process was $30 \mathrm{~mA} \mathrm{~cm}{ }^{-2}$, with a periodic sequence of turn-on $(0.3 \mathrm{~ms})$ and turn-off $(0.15 \mathrm{~ms})$. The actual $\mathrm{Pt}$ loading of the Ir@Pt/C cathode, determined by AAS, was $0.044 \mathrm{mg} \mathrm{cm}^{-2}$. In this work, all Ir@Pt/C electrodes prepared were used as the cathodes. The anode was prepared via a CCM method in which commercial JM Hispec $4100 \mathrm{Pt} / \mathrm{C}$ catalyst was used. The anode Pt loading was $0.1 \mathrm{mg} \mathrm{cm}^{-2}$ for all MEAs. For a fair comparison, a MEA with JM Hispec $4100 \mathrm{Pt} / \mathrm{C}$ was prepared, in which both the anode and cathode Pt loading was $0.1 \mathrm{mg}$ $\mathrm{Pt} \mathrm{cm}^{-2}$.

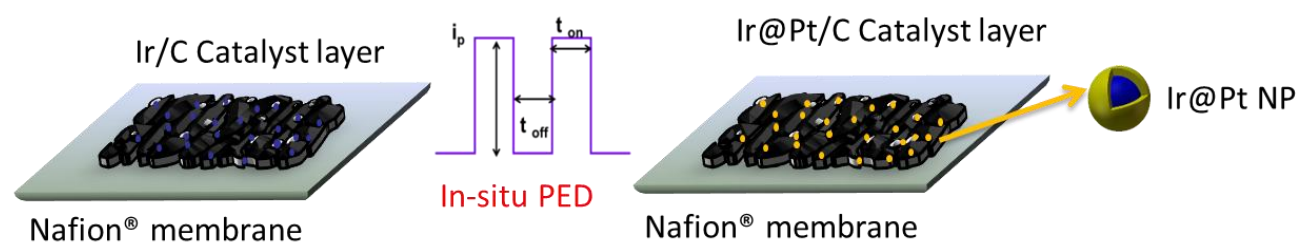

Fig.1. Illustration of in-situ preparation of core-shell nanoparticles

\subsection{Single-cell Evaluations of the MEAs}

The MEAs were sandwiched between two gas diffusion layers, which were prepared by spraying a carbon-Teflon ${ }^{\circledR}$ mixture on a pre-treated carbon paper for the anode and cathode. They were then assembled into a single fuel cell for testing and evaluations.

The measurements were performed using a Fuel Cell Testing System (Arbin Instruments, USA). The cell temperature was maintained at $70^{\circ} \mathrm{C} . \mathrm{H}_{2}$ as fuel and air as 
oxidant gas were fully humidified (100\% humidification, the temperature for hydrogen and air were both set at $70^{\circ} \mathrm{C}$ ) before feeding at a flow rate of $120 \mathrm{ml} \mathrm{min}^{-1}$ for $\mathrm{H}_{2}$ and $800 \mathrm{ml} \mathrm{min}{ }^{-1}$ for air, respectively. The back pressure for both anode and cathode was $0.2 \mathrm{MPa}$.

\subsection{Characterizations of the Catalysts and MEAs}

After single cell evaluation, Ir@Pt/C was peeled off from the MEA's cathode by ethanol and the morphology was observed using a high-resolution transmission electron microscope (JEOL JEM-2010HR, Japan). High-angle annular dark field (HAADF) images and energy dispersive spectrometer (EDS) elemental line scan analysis were obtained using scanning transmission electron microscopy (STEM) mode on an aberration-corrected FEI Titan $\mathrm{G}^{2}$ 60-300 field emission transmission electron microscope (FEI), operated at $300 \mathrm{kV}$ ( $\left.\alpha_{\max } \sim 100 \mathrm{mrad}\right)$. The NP crystal structure was determined by X-ray diffraction (XRD, TD-3500, Tongda, China) using filtered $\mathrm{Cu} \mathrm{K} \alpha$ radiation at $40 \mathrm{kV}$ and $30 \mathrm{~mA}$, in the $2 \theta$ region between $10^{\circ}$ and $80^{\circ}$ with a scan rate of $4^{\circ} \mathrm{min}^{-1}$. X-ray photoelectron spectroscopy (XPS) on a PerkinElmer PHI1600 system (PerkinElmer, USA) using a single Mg Ka X-ray source operating at $300 \mathrm{~W}$ and $15 \mathrm{kV}$. The binding energies (BEs) were calibrated using the $\mathrm{C} 1 \mathrm{~s}$ peak of graphite at $284.5 \mathrm{eV}$ as the reference before peak deconvolution.

Electrochemical impedance spectroscopy (EIS) and cyclic voltammetry (CV) were performed on a Zahner IM6e electrochemistry station (Zahner, Germany). The EIS measurements were carried out at a cell potential of $0.8 \mathrm{~V}$ in the frequency range 
of $0.1-1000 \mathrm{~Hz}$ using a sinusoidal amplitude modulation of $\pm 5 \mathrm{mV}$ about the applied potential. Cyclic voltammetric (CV) measurements were conducted at room temperature $\left(25^{\circ} \mathrm{C}\right)$ using humidified $\mathrm{N}_{2}$ at the cathode (working electrode) and humidified $\mathrm{H}_{2}$ at the anode (reference electrode) of the MEA. The humidification temperatures for $\mathrm{N}_{2}$ and $\mathrm{H}_{2}$ in $\mathrm{CV}$ measurements are both $25^{\circ} \mathrm{C}$.

\subsection{DFT calculations}

First-principles calculations based on Density Functional Theory (DFT) were performed in VASP to understand the enhanced ORR behavior in Pt coated Ir nano spheres. Revised PBE exchange-correlation functional was used to better describe adsorption behavior on noble metal surfaces. Relative settings include spin polarized calculations in all models, $400 \mathrm{eV}$ energy cutoff with $3 \times 3 \times 1$ Gamma-point k-point mesh (Isolated adsorbate used single Gamma k-point). Gaussian smearing method with smearing broadening $0.2 \mathrm{eV}$ was applied on electronic density of states near Fermi level. Convergence criteria include an energy convergence of $10^{-4} \mathrm{eV}$ and atomic force convergence of $0.05 \mathrm{eV} / \AA . \mathrm{A} 4 \times 4$ in-plane extension of primitive FCC cell in Pt and Ir, together with a six atomic-layer slab (96 atoms/ perfect slab) was used to eliminate spurious adsorbate-adsorbate interactions and ensure fully surface relaxations. The binding (adsorption) energy of $\mathrm{O}$ and $\mathrm{OH}$ on $\mathrm{Pt}$, $\mathrm{Ir}$ and Pt-coated Ir surfaces was calculated using the equation shown below:

$$
E_{\text {binding }}=E_{\text {adsorbed }}-E_{\text {clean }}-E_{\text {adsorbate }}
$$

where $E_{\text {adsorbed }}$ is the energy of substrate surface with the adsorbate sitting on top, $E_{\text {clean }}$ and $E_{\text {adsorbate }}$ are the energy of clean surface and isolated adsorbate. 


\section{Results and Discussion}
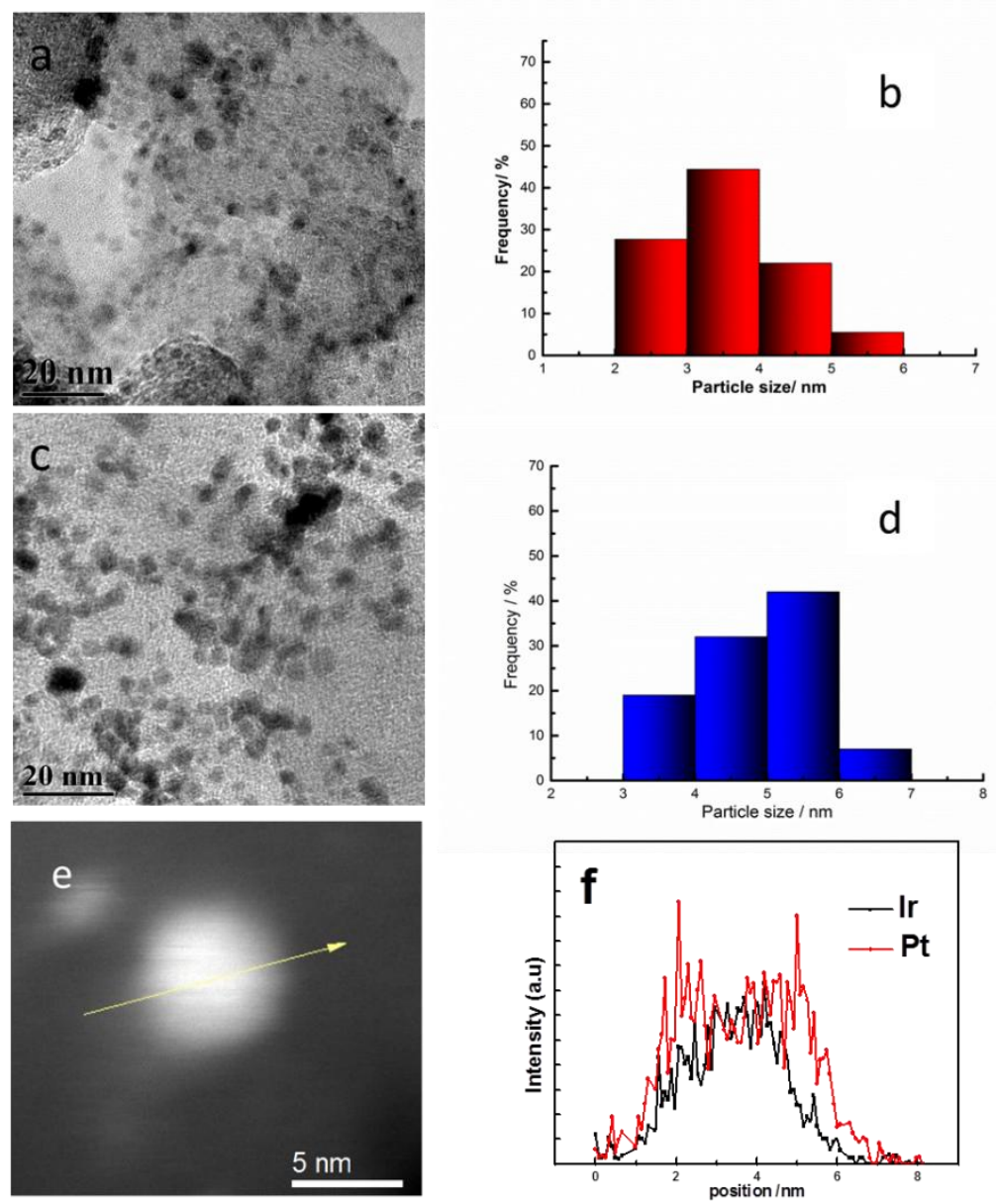

Fig. 2 TEM image and the corresponding particle size histogram of $\operatorname{Ir} / \mathrm{C}(\mathrm{a}, \mathrm{b})$ and Ir@Pt/C (c, d); HAADF STEM image of a single Ir@Pt/C particle (e) and the corresponding EDS line scan profiles (f).

TEM images of $\mathrm{Ir} / \mathrm{C}$ and $\mathrm{Ir} @ \mathrm{Pt} / \mathrm{C}$ and their corresponding particle size distribution histograms are given in Fig. 2. The particle size of $\mathrm{Ir} @ \mathrm{Pt} / \mathrm{C}$ (Fig. 2c) was slightly bigger than that of Ir/C (Fig. 2a) due to the direct deposition of Pt shell on Ir 
core. This could be further elucidated from the particle size distribution histogram since the mean particle size increased from ca. $4.1 \mathrm{~nm}$ for Ir/C (Fig. 2b) to ca. $5.3 \mathrm{~nm}$ for Ir@Pt/C (Fig. 2d). Assuming that the spherical Ir core (4.1 nm in diameter) and Ir@Pt (5.3 nm in diameter) are ideally intact, the thickness of the Pt shell was calculated to be $0.6 \mathrm{~nm}$, corresponding to two atomic layers. An increase in particle size strongly signified that a Pt shell was deposited on the surface of the Ir NPs to form the core-shell structured Ir@Pt/C [17, 23]. In addition, it can be observed that the core-shell Ir@Pt NPs were homogenously dispersed on the carbon support and had a narrow size distribution.

The core-shell structure of Ir@Pt catalyst was further confirmed by high-angle annular dark-filed (HAADF) TEM measurement in Fig. 2e and EDS line scanning in Fig. 2f. Pt was found to be highly populated at the edge of Ir@Pt, which strongly demonstrated the core-shell structure of the Ir@Pt/C nanoparticles.

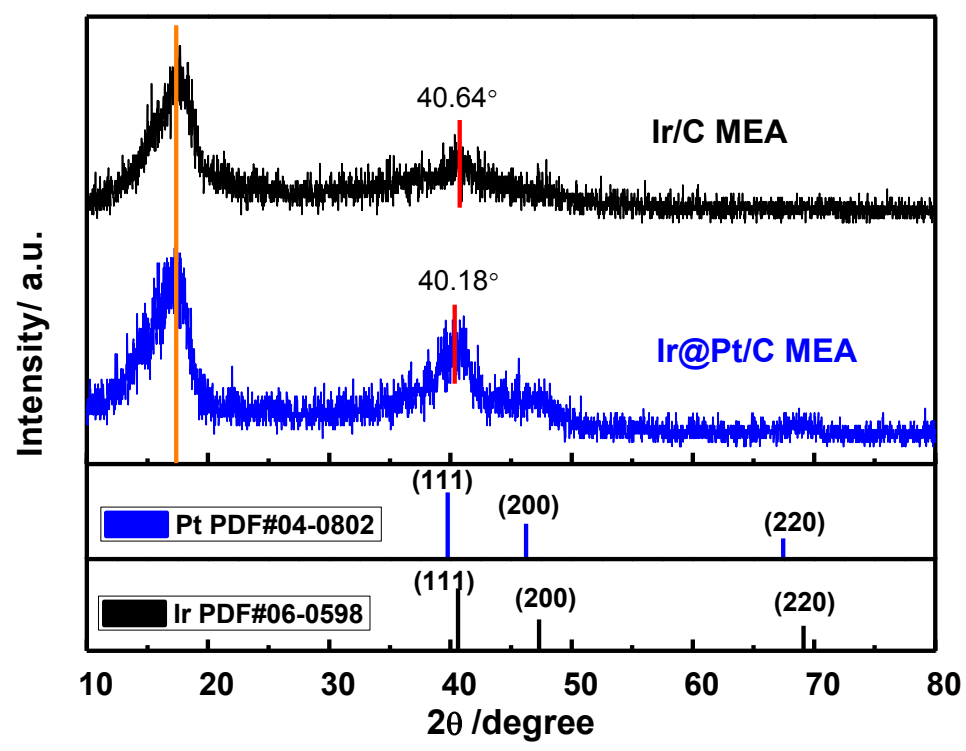


Fig. 3 X-ray diffraction patterns of Ir/C MEA, PDF card for Ir standard (shown as black lines), Ir@Pt/C MEA, and PDF card for Pt standard (shown as blue lines).

Fig. 3 shows the XRD patterns of MEAs with Ir/C and Ir@Pt/C MEA as the cathode catalysts. The line broadening at approximately $16.9^{\circ}$ is generally attributed to the Nafion ${ }^{\circledR}$ membrane [30] . Before Pt deposition, the cathode catalyst layer with Ir/C exhibited weak diffractions, which may be attributed to relatively low Ir loading $\left(0.039 \mathrm{mg} \mathrm{cm}^{-2}\right)$. Nafion ${ }^{\circledR}$ may interfere with detection signal since its content in the catalyst layer is high. A diffraction peak, although weak in intensity, was detectable at $2 \theta$ of $40.6^{\circ}$ and could be indexed to the (111) plane of face centered cubic (f.c.c) iridium, according to the standard Ir PDF card (indicated by black vertical lines).

A significant change in XRD pattern was found after the deposition of a Pt layer. The broad diffraction peaks at $2 \theta$ angle of $39.7^{\circ}, 46.1^{\circ}$ and $67.5^{\circ}$ (indexed by the standard Pt PDF card, the blue vertical lines in Fig. 3) in the pattern of the Ir@Pt/C MEA were evolved, indicating the existence of Pt nanoparticle on the Ir surface. It is to be noted that there were no sharp diffraction peaks of Pt in the XRD pattern, which were agreed with the findings in the literature $[23,31]$. It is suggested that in this case, Pt atoms were not covered by the Nafion ${ }^{\circledR}$ ionomer and were exclusively nucleated on the Ir surface in the second step of the preparation process and reduced as a shell, resulting in the formation of highly dispersed Ir@Pt/C catalyst layer. Additionally, the lattice parameter for Ir@Pt/C is $3.873 \AA$, which is slightly shrunk than that of pure $\mathrm{Pt}$ $(3.923 \AA)$ and expanded than that of $\operatorname{Ir}(3.846 \AA)$. Compared with the standard Pt XRD pattern shown by the blue vertical lines in the Fig. 3, the (111) diffraction peak 
position of the Ir@Pt/C MEA was slightly shifted to a higher $2 \theta$ angle. It may be concluded from the information obtained by XRD pattern and TEM image, Pt would selectively nucleate on the Ir surface during the PED process and favor the formation of Ir@Pt.
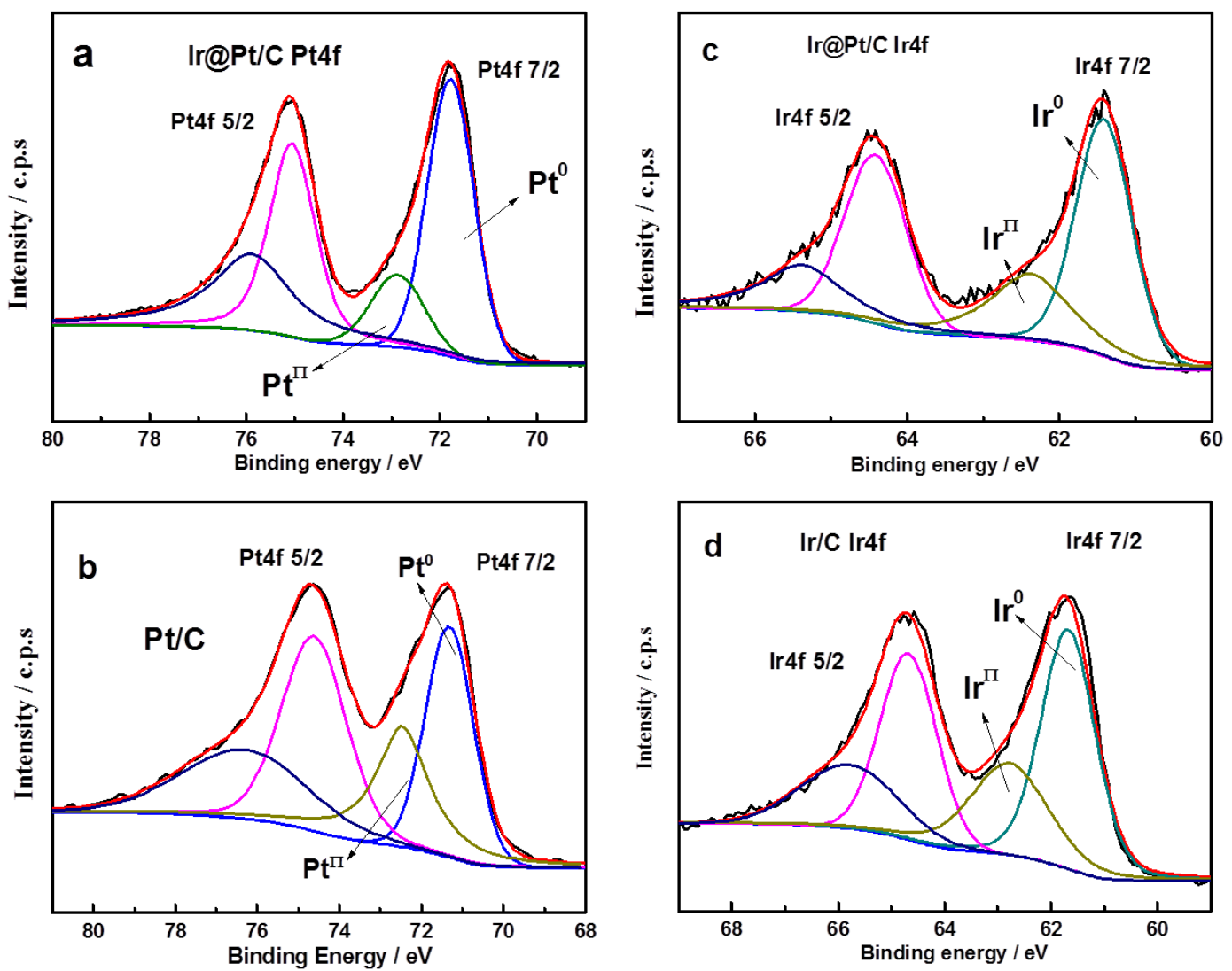

Fig. 4 XPS spectra of (a) Pt 4f in Ir@Pt/C, (b) Pt 4f in JM Pt/C, (c) Ir 4f in $\mathrm{Ir} @ \mathrm{Pt} / \mathrm{C}$ and $(\mathrm{d}) \mathrm{Ir} 4 \mathrm{f}$ in Ir/C.

XPS measurements were conducted on the $\mathrm{Ir} @ \mathrm{Pt} / \mathrm{C}, \mathrm{Pt} / \mathrm{C}$ and $\mathrm{Ir} / \mathrm{C}$ for the $\mathrm{Pt} 4 \mathrm{f}$ and Ir $4 \mathrm{f}$ regions to further investigate the presence of Pt shell on Ir core and the possible synergic effects induced. The Pt 4f XPS spectra and core-level split of Ir@Pt/C and Pt/C were shown in Fig. 4a and Fig. 4b, respectively. Differences 
between Fig. 4a and Fig. 4b are obvious: the core-level binding energies of $\mathrm{Pt} 4 \mathrm{f}$ in the Ir@Pt/C are all positively shifted relative to those for monometallic Pt. The Pt $4 \mathrm{f}_{7 / 2}$ binding energy of $\mathrm{Ir} @ \mathrm{Pt} / \mathrm{C}(71.80 \mathrm{eV})$ was much higher than that of $\mathrm{Pt} / \mathrm{C}(71.32$ $\mathrm{eV}$ ), suggesting a considerable tuning of the Pt surface electronic structure by Ir underneath. This was consistent with our previous finding [12, 23].

The Ir XPS spectra in Fig. 4(c) and (d) show two doublets, which can be assigned to metallic $\operatorname{Ir}(0)$ and oxidized $\operatorname{Ir}(\mathrm{II})$. The $\operatorname{Ir} 4 \mathrm{f}_{7 / 2}$ signal of the $\operatorname{Ir} @ \mathrm{Pt} / \mathrm{C}$ shifted negatively to a lower binding energy $(61.38 \mathrm{eV})$ relative to that for $\mathrm{Ir} / \mathrm{C}(61.68 \mathrm{eV})$. The electron transfer from Pt to Ir may indicate the interaction between the Pt shell and Ir core and therefore result in improved ORR mass activity.

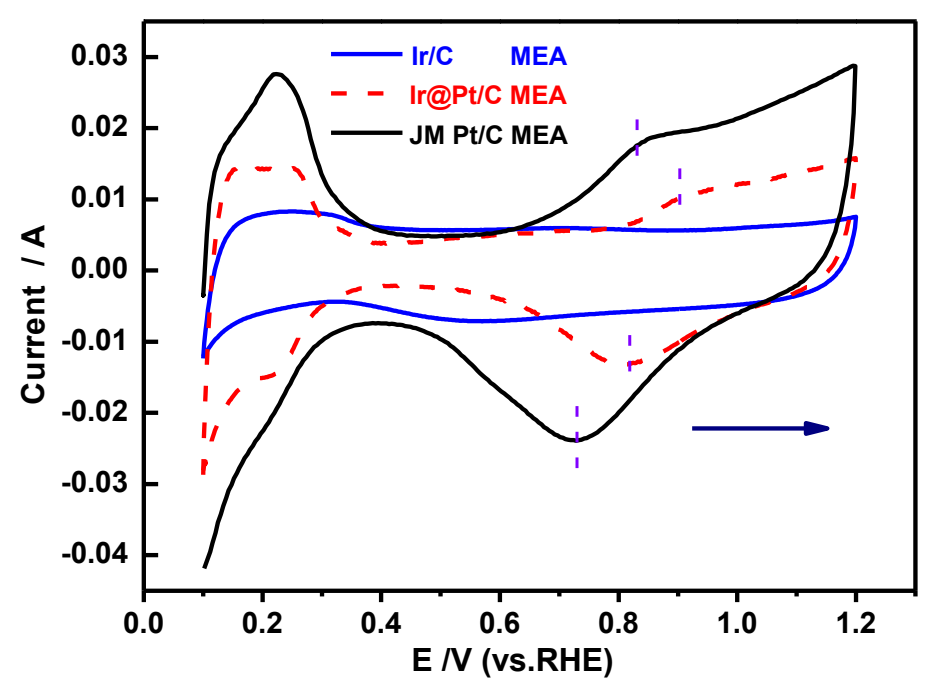

Fig. 5 Cyclic voltammograms of the MEAs with the Pt/C, Ir/C and $\mathrm{Ir} @ \mathrm{Pt} / \mathrm{C}$ as the cathodes. The measurements were carried out in a single cell at room temperature, using humidified $\mathrm{N}_{2}$ at the cathode (working electrode) and humidified $\mathrm{H}_{2}$ at the anode (counter electrode cum reference electrode). Scan rate: $0.05 \mathrm{~V} \mathrm{~s}^{-1}$. 
Fig. 5 shows the in situ CVs of the cathodes with the Pt/C, Ir/C and the Ir@Pt/C MEA. The measurements were conducted in a single cell in which hydrogen and nitrogen were introduced in the anode chamber (used as the reference) and cathode chamber, respectively. No obvious hydrogen adsorption/desorption peaks were found in the hydrogen under-potential region for the Ir/C MEA. However, after the deposition of a Pt layer, both adsorption/desorption peaks became observable, and the peak intensities and integrated $\mathrm{H}$ desorption/adsorption areas in the region of $0.1 \sim 0.35$ $\mathrm{V}$ increased significantly due to Pt coverage. On the other hand, the double-layer potential region $(0.35 \sim 0.6 \mathrm{~V})$ of the Ir/C MEA was quite different from that of the Ir@Pt/C MEA. Pt deposition on the Ir/C leads to a significant change in the double layer region, which was consistent with other reports [15]. Furthermore, the on-set Pt oxidation potential at $0.86 \mathrm{~V}$ in the forward scan and the reduction potential at $0.82 \mathrm{~V}$ were evident for the Ir@Pt/C MEA, which further confirmed the deposition of the $\mathrm{Pt}$ layers. The disappearance of the characteristic features of the $\mathrm{Ir} / \mathrm{C}$ in the double layer region and the evolution of the $\mathrm{Pt}$ oxidation/reduction couple at $0.7 \sim 0.9 \mathrm{~V}$ after $\mathrm{Pt}$ deposition for the Ir@Pt/C manifested the formation of core-shell structured Ir@Pt. It might be noted that the Pt oxidation peak for the Ir@Pt/C MEA shifted positively relative to that of bulk Pt. One hypothesis is that the Ir sub-layers may have a significant impact on the adsorption behavior of $\mathrm{OH}$ species at the Pt surface [33-35]. The CVs showed that the formation of Pt-OH on the Ir@Pt/C MEA was retarded and the higher $\mathrm{Pt}-\mathrm{OH}$ formation potential could lead to the expected improvement on 
ORR activity [36]. On the other hand, the positive shift on the Pt-OH formation potential may also indicate an interaction between the Pt in the shell layer and the Ir in the core.
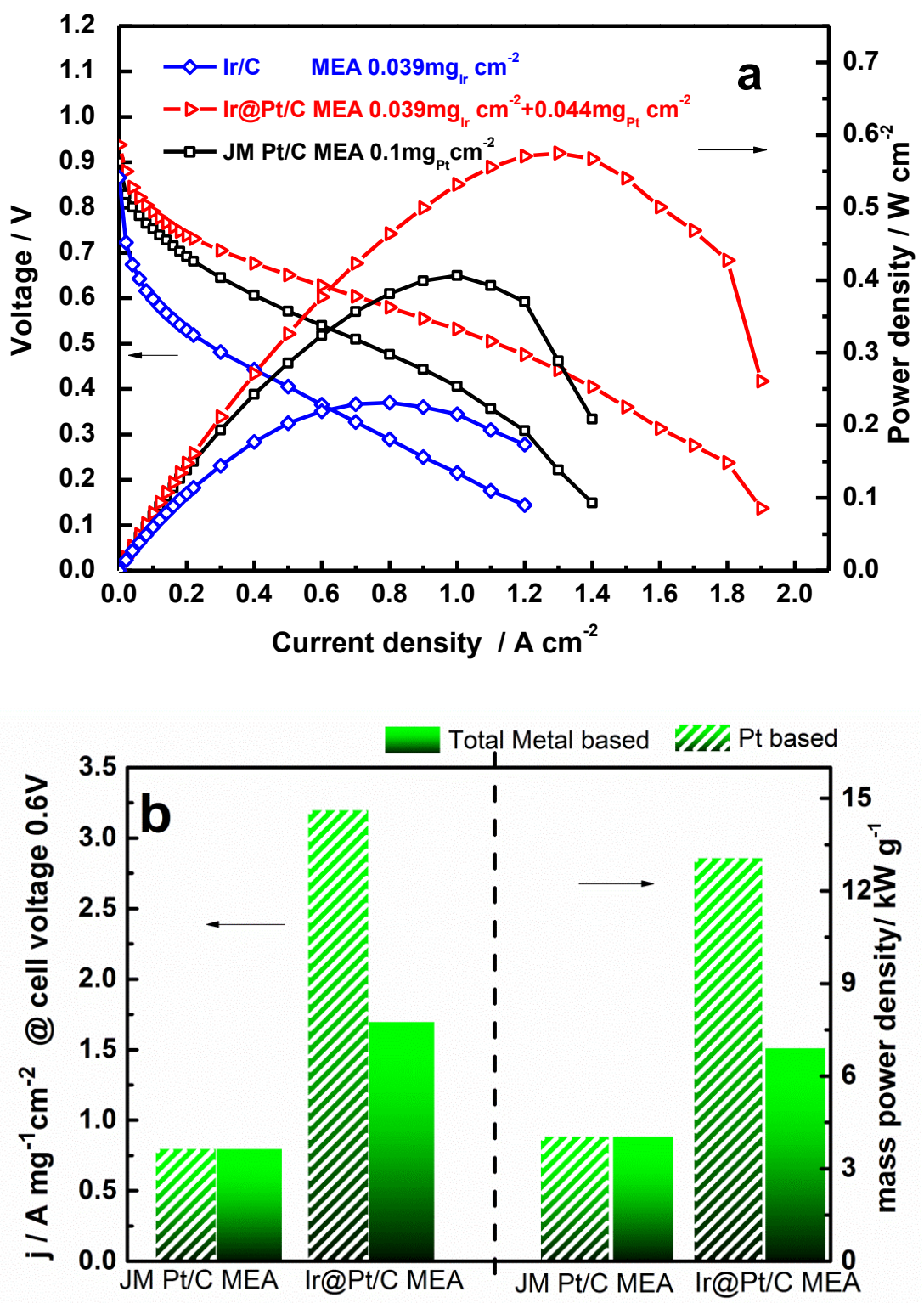

Fig. 6 (a) Polarization curves for the Ir@Pt/C MEA (Pt loading $0.044 \mathrm{mg} \mathrm{cm}^{-2}$ ), the JM Pt/C MEA (Pt loading $0.1 \mathrm{mg} \mathrm{cm}^{-2}$ ) and the Ir/C MEA (Ir loading 0.039 $\mathrm{mg} \mathrm{cm}{ }^{-2}$ ) as the cathode. All the MEAs have the same anode Pt loadings (JM Pt/C $0.1 \mathrm{mg} \mathrm{cm}^{-2}$ ). (b) Comparison in mass activities. Solid rectangles represent mass 
activities in terms of metal and the dashed ones display mass activity normalized to $\mathrm{Pt}$.

Fig. 6a shows the single cell performance of the MEAs with different cathodes under the same operating conditions $\left(70^{\circ} \mathrm{C}\right.$ for the cell, $\mathrm{H}_{2}$ and air; $5 \mathrm{~cm}^{2}$ effective geometric surface area; 30 psi back pressure). In the Fig. 6a, it can be seen that the Ir/C MEA presents the poorest cell performance with the peak power density of merely $200 \mathrm{~mW} \mathrm{~cm}^{-2}$. After decorating the Ir surface with a trace amount of Pt $(0.044$ $\mathrm{mg} \mathrm{cm}^{-2}$ ), the single cell performance of the $\mathrm{Ir} @ \mathrm{Pt} / \mathrm{C} \mathrm{MEA}$ in the entire electrochemical reaction region enhances dramatically if compared with that of the JM Pt/C MEA and Ir/C MEA. The voltage drop at the lower scale of current density can be ascribed to the sluggish kinetics of oxygen reduction reaction at cathode, which is mainly determined by the intrinsic property of the electrode. The polarization curve of the Ir@Pt/C MEA exhibits much more moderate voltage drop at low current density than the other MEAs, signifying its improved oxygen reduction kinetics. In particular, the voltage drop of the Ir@Pt/C MEA at the higher scale of current density due to mass transport limitations is markedly curbed compared with that of the JM $\mathrm{Pt} / \mathrm{C}$ MEA. This can be attributed to the unique structure of the electrode, in which thinner catalyst layer allows for fast delivery of protons and promotes for the diffusion and transportation of gases. As a combined result of above, local mass transport is improved in the $\mathrm{Ir} @ \mathrm{Pt} / \mathrm{C}$, leading to the enhanced cell performance. It is worth noting that superb cell performance (output power density at $0.6 \mathrm{~V}, 430 \mathrm{~mW}$

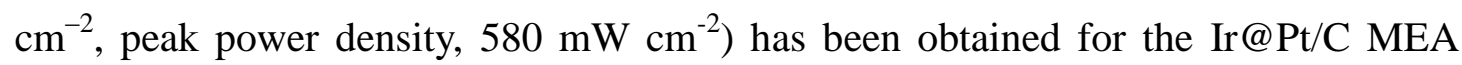


when the $\mathrm{Pt}$ loading was as low as $0.044 \mathrm{mg} \mathrm{cm}^{-2}$. Moreover, a substantial improvement in Pt utilization efficiency for the Ir@Pt/C at the cathode is evident in Fig. 6(b). If normalized to Pt, the mass activity for the $\operatorname{Ir} @ \mathrm{Pt} / \mathrm{C}$ is $13.08 \mathrm{~kW} \mathrm{gPt}^{-1}$, which is 3.3 times higher than that of the JM Pt/C MEA. Taking the total amount of metal ( $\mathrm{Ir}+\mathrm{Pt})$ into consideration, the mass activity of the Ir@Pt/C MEA still surpasses that of the JM Pt/C MEA. It can be concluded that the single cell evaluation results indeed met with our expectation, the tailor-made $\mathrm{Ir} @ \mathrm{PtC}$ overcame the sluggish kinetic of the oxygen reduction reaction at the cathode with demonstrated high noble metal utilization.

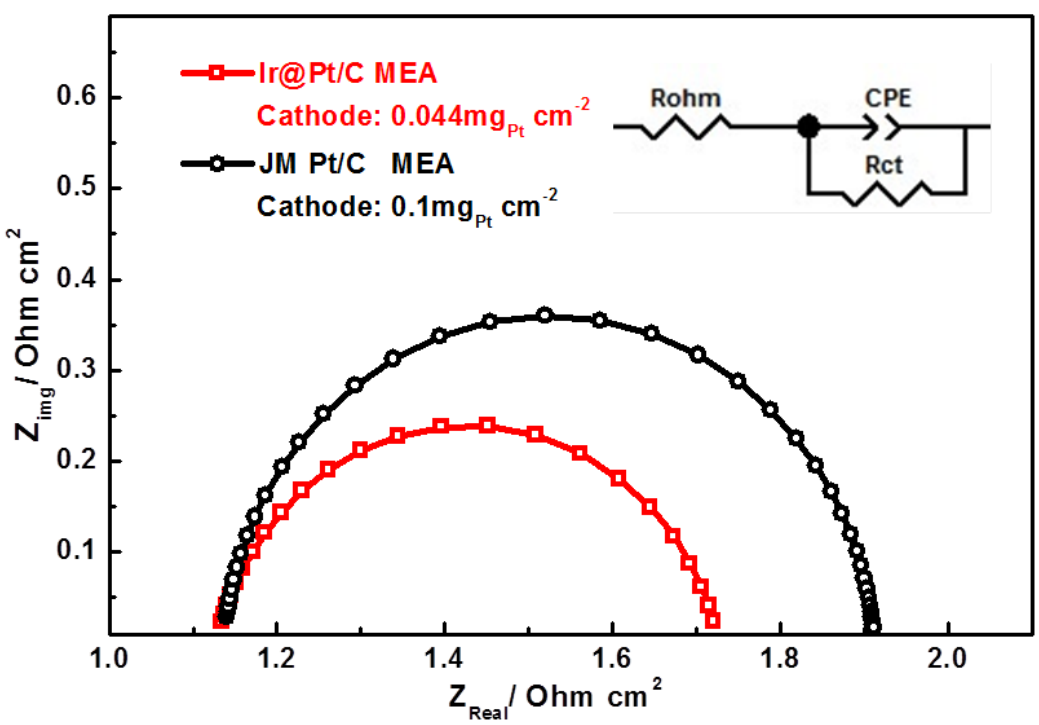

Fig.7 In situ electrochemical impedance curves of the Ir@ Pt/C MEA and JM Pt/C MEA at $0.8 \mathrm{~V}$.

Table. 1 Resistance of the single cell with two types of MEAs

\begin{tabular}{lll}
\hline Sample & Ir@Pt/C MEA & JM Pt/C MEA \\
\hline
\end{tabular}


Fig. 7 shows the in situ electrochemical impedance results for the two MEAs. Through simulation with $\mathrm{RC}$ equivalent circuit in the Fig. 7, the cell resistances $(\mathrm{R} \Omega)$ and charge transfer resistances (Rct) of the two MEAs could be calculated and they are listed in Table 1. The results were in good agreement with their corresponding single-cell performance. Only one semicircular loop can be observed in the Nyquist plot because the electrode process is dominated by the ORR at low current densities. It can be seen that the Ir@Pt/C MEA shows the smallest charge transfer resistance, demonstrating the superiority of the this novel MEA with high Pt utilization efficiency and improved single cell performance.

Table. 2 Calculated $\mathrm{O}$ and $\mathrm{OH}$ binding energy on Pr, Ir and $\mathrm{Ir} @ \mathrm{Pt}_{2 \mathrm{ML}}$ surfaces. All values are in $\mathrm{eV}$.

\begin{tabular}{llll}
\hline $\begin{array}{l}\text { Surface } \\
\text { models/Adsorbate }\end{array}$ & $\mathbf{I r}(\mathbf{1 1 1})$ & $\mathbf{P t}(\mathbf{1 1 1})$ & $\mathbf{I r} @ \mathbf{P t}_{\mathbf{2 M L}}$ \\
\hline$* \mathbf{O}$ & -4.82 & -4.20 & -3.74 \\
$* \mathbf{O H}$ & -2.12 & -1.59 & -1.32 \\
\hline
\end{tabular}




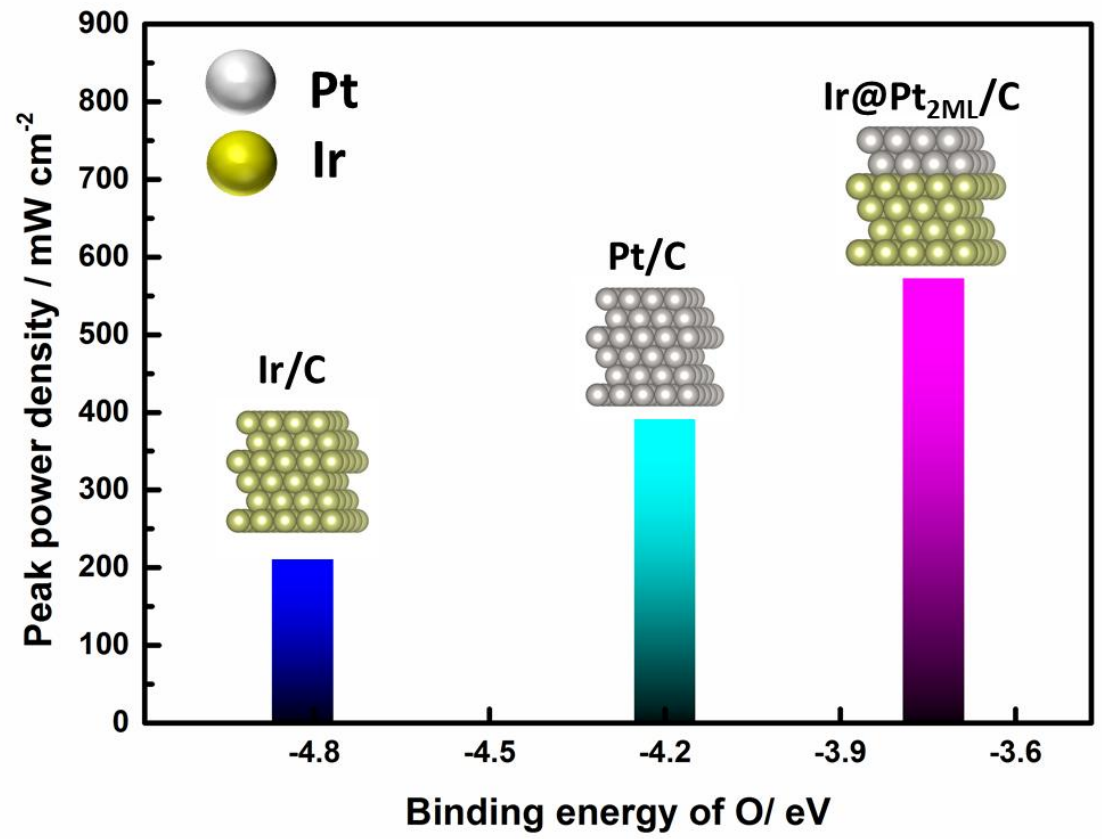

Fig.8 Binding energy of oxygen (BEO) of Ir, $\mathrm{Pt}, \mathrm{Ir} @ \mathrm{Pt}_{2 \mathrm{ML}}$ against the peak power density of Ir/C, Pt/C and Ir@Pt/C.

To theoretically understand the experimental trend of ORR activity for each catalyst, we performed the DFT calculations systematically. The calculated binding energy of $\mathrm{O}$ and $\mathrm{OH}$ shown in Table.2 is well-known to describe the ORR activity according to the previous research [38]. By slightly weakening the Pt-O binding energy, the ORR activity can be increased dramatically. From the table, we can see Ir has the strongest binding energy of both $\mathrm{O}$ and $\mathrm{OH}$, exceeding the values in $\mathrm{Pt}$ by $\sim 0.6 \mathrm{eV}$, respectively. On the other hand, the 2 mono-layer Pt coated on Ir (Ir@Pt $2 \mathrm{ML}$ ) has the binding of $\mathrm{O} \sim 0.47 \mathrm{eV}$ weaker and $\mathrm{OH} \sim 0.27 \mathrm{eV}$ weaker than that in $\mathrm{Pt}$, which can be proven experimentally shown in Fig.5 by positively shifting the oxidation peaks to higher potentials. Fig.8 exhibited the BEOs against the peak power density for Ir/C, Pt/C and Ir@Pt/C MEA. It can be seen that Ir and Pt bind oxygen too 
tightly, while Ir@Pt has a slightly weaker binding energy of $\mathrm{O}$, which leading to the improved ORR performance.

\section{Conclusion}

An Ir@Pt/C MEAs were successfully prepared by in situ deposition of a Pt thin shell on Ir NPs in an Ir/C cathode catalyst layer and cathode cell performance was investigated. For optimal MEA prepared in this work, its performance could reach $13.08 \mathrm{~kW} \mathrm{~g}^{-1} \mathrm{Pt}$, which was three fold than that of a MEA prepared with JM Pt/C catalyst as cathode, demonstrating the superior Pt utilization efficiency of MEA prepared with this novel approach. It is interesting that the existence of the interaction between the Pt at shell layer and Ir core was revealed by the XRD and XPS results, and further confirmed by the DFT calculations, this interaction cause the weaker binding energy of $\mathrm{O}$ and $\mathrm{OH}$ on $\mathrm{Ir}_{\mathrm{P}} \mathrm{Pt}_{2 \mathrm{ML}}$ than on $\mathrm{Pt}$, and finally results in improved ORR activity. In conclusion, the significantly enhanced performance of as-prepared MEA may be attributed to the ultra-high Pt dispersion and exposure/utilization, resulted from in-situ deposition approach, and the interactions between Pt at shell and Ir core. It should be mentioned that Pt loading can be greatly reduced, but Ir as noble metal used in this system may weaken the advantages compared to low-loaded PtM ( $\mathrm{M}=\mathrm{Ni}, \mathrm{Co})$ catalysts [2]. The searching for the cheap core materials is forthcoming. This work may provide a new pathway to the realization of low Pt loadings PEM fuel cells. 


\section{Acknowledgments}

This work was supported by the State's Key Project of Research and Development Plan of China (Project No 2016YFB0101201), the National Natural Science Foundation of China (NSFC Project Nos. 21476088, 51302091, U1301245), Natural

Science Foundation of Guangdong Province (Project Nos. 2014A010105041, 2015A030312007), Guangdong Provincial Department of Science and Technology(Project No. 2015B010106012), Educational Commission of Guangdong Province (Project No. 2013CXZDA003), and Guangzhou Science Technology Innovation Committee(Project No. 2016201604030012).

\section{References}

[1] S. Holdcroft, Chem. Mater. 26 (2014) 381-393.

[2] M. K. Debe, Nature 486 (2012) 43-51.

[3]H. A. Gasteiger, N. M. Marković, Science 324 (2009) 48-49.

[4] A. G. Hubert, S. K. Shyam, S. Bhaskar, T. W. Frederick, Appl. Catal. B 56 (2005) 9-35.

[5] A. Rabis, P. Rodriguez, T. J. Schmidt, ACS Catal. 2 (2012) 864-890.

[6] F. Luo, S. Liao, D. Dang, Y. Zheng, D. Xu, H. Nan, T. Shu, Z. Fu, ACS Catal. 5 (2015) 2242-2249.

[7] S. Woo, I. Kim, J. K. Lee, S. Bong, J. Lee, H. Kim, Electrochim. Acta 56 (2011) 3036-3041.

[8] J. Li, H. Tang, R. Chen, D. Liu, Z. Xie, M. Pan, S. P. Jiang, J. Mater. Chem. A 3 (2015) 15001-15007.

[9] D. Banham, F. Feng, K. Pei, S. Ye, V. Birss, J. Mater. Chem. A 1 (2013) 2812.

[10] H. Yang, Angew. Chem. 50 (2011) 2674-2676.

[11] D. Wang, H. L. Xin, R. Hovden, H. Wang, Y. Yu, D. A. Muller, F. J. DiSalvo, H. D. Abruña, Nat. Mater. 12 (2013) 81-87.

[12] D. Chen, R. Chen, D. Dang, T. Shu, H. Peng, S. Liao, Electrochem. Commun. 46 (2014) 115-119.

[13] H. Nan, X. Tian, J. Luo, D. Dang, R. Chen, L. Liu, X. Li, J. Zeng, S. Liao, J. Mater. Chem. A 4 (2016) 847-855.

[14 ]S. Yang, D. Y. Chung, Y.-J. Tak, J. Kim, H. Han, J.-S. Yu, A. Soon, Y.-E. Sung, H. Lee, Appl. 
Catal. B 174-175 (2015) 35-42.

[15] L. Yang, M. B. Vukmirovic, D. Su, K. Sasaki, J. A. Herron, M. Mavrikakis, S. Liao, R. R. Adzic, The J. Phys. Chem. C 117 (2013) 1748-1753.

[16] Y. Kim, Y. Noh, E. J. Lim, S. Lee, S. M. Choi, W. B. Kim, J. Mater. Chem. A 2 (2014) 6976.

[17] K. Christian, C. Xingxing, P. Andrea, S. Stefanie, S. Christoph, S. Wolfgang, B. Michael, ChemPhysChem 11 (2010) 2854-2861

[18] Q. Jia, K. Caldwell, K. Strickland, J. M. Ziegelbauer, Z. Liu, Z. Yu, D. E. Ramaker, S. Mukerjee, ACS Catal. 5 (2014) 176-186.

[19] X. Tian, J. Luo, H. Nan, H. Zou, R. Chen, T. Shu, X. Li, Y. Li, H. Song, S. Liao, R. R. Adzic, J. Am. Chem. Soc. 138 (2016) 1575-1583.

[20] Y. Ra, J. Lee, I. Kim, S. Bong, H. Kim, J. Power Sources 187 (2009) 363-370.

[21] M. Mougenot, A. Caillard, P. Brault, S. Baranton, C. Coutanceau, Int. J. Hydrogen Energy 36 (2011) 8429-8434.

[22] D. Dang, H. Zou, Z. a. Xiong, S. Hou, T. Shu, H. Nan, X. Zeng, J. Zeng, S. Liao, ACS Catal. 5 (2015) 4318-4324.

[23] D. Dang, S. Liao, F. Luo, S. Hou, H. Song, P. Huang, J. Power Sources 260 (2014) 27-33.

[24 ]G. Zhang, Z.-G. Shao, W. Lu, G. Li, F. Liu, B. Yi, Electrochem. Commun. 22 (2012) 145-148.

[25] K. S. Lee, S. J. Yoo, D. Ahn, T. Y. Jeon, K. H. Choi, I. S. Park, Y. E. Sung, Langmuir 27 (2011) 3128-3137.

[26] H. Gao, S. Liao, J. Zeng, Y. Xie, J. Power Sources 196 (2011) 54-61.

[27] H.N. Su, S.J. Liao, T. Shu, H.L. Gao, J. Power Sources 195 (2010) 756-761.

[28] B. Richter, H. Kuhlenbeck, H. J. Freund, P. Bagus, Phys. Rev. Lett. 93 (2004)

[29] I. K. Lidia, I. K. Nina, V. K. Sergei, I. Z. Vladimir, S. L. Alexander, M. K. Ksenia, V. K. Natalia, T. Zbigniev, Appl. Catal. A 427-428 (2012) 8-15

[30] Zhanli Chai, Cheng Wang, Hongjie Zhang, Cara. M. Doherty, Bradley. P. Ladewig, Anita. J. Hill, H.Wang. Adv. Funct. Mater. 20 (2010) 4394-4399.

[31] Y. C. Hsieh, Y. Zhang, D. Su, V. Volkov, R. Si, L. Wu, Y. Zhu, W. An, P. Liu, P. He, S. Ye, R. R. Adzic, J. X. Wang, Nat. Commun. 4 (2013) 2466.

[32] T. Shu, D. Dang, D.W. Xu, R. Chen, S.j. Liao, C.T.Hsieh, A. Su, H.Y. Song, L. Du, Electrochim. Acta 177 (2015) 168-173.

[33] Y. Xing, Y. Cai, M. B. Vukmirovic, W.P. Zhou, H. Karan, J. X. Wang, R. R. Adzic, J. Phys.Chem. Letters 1 (2010) 3238-3242.

[34] J. Zhang, Y. Mo, M. B. Vukmirovic, R. Klie, K. Sasaki, R. R. Adzic, J. Phys. Chem. B 108 (2004) 10955-10964.

[35] J. Wang, N. Markovic, R. Adzic, J. Phys. Chem. B 108 (2004) 4127-4133.

[36] M. Shao, K. Sasaki, N. Marinkovic, L. Zhang, R. Adzic, Electrochem. Commun. 9 (2007) 2848-2853.

[37] J. Kitchin, J. Nørskov, M. Barteau, J. Chen, Phys. Rev. Lett. 93 (2004)

[38] J. Wang, H. Inada, L. Wu, Y. Zhu, Y. Choi, P. Liu, W.-P. Zhou, R. Adzic, J. Am. Chem. Soc. 131 (2009) 17298-17302. 
Graphical Abstract
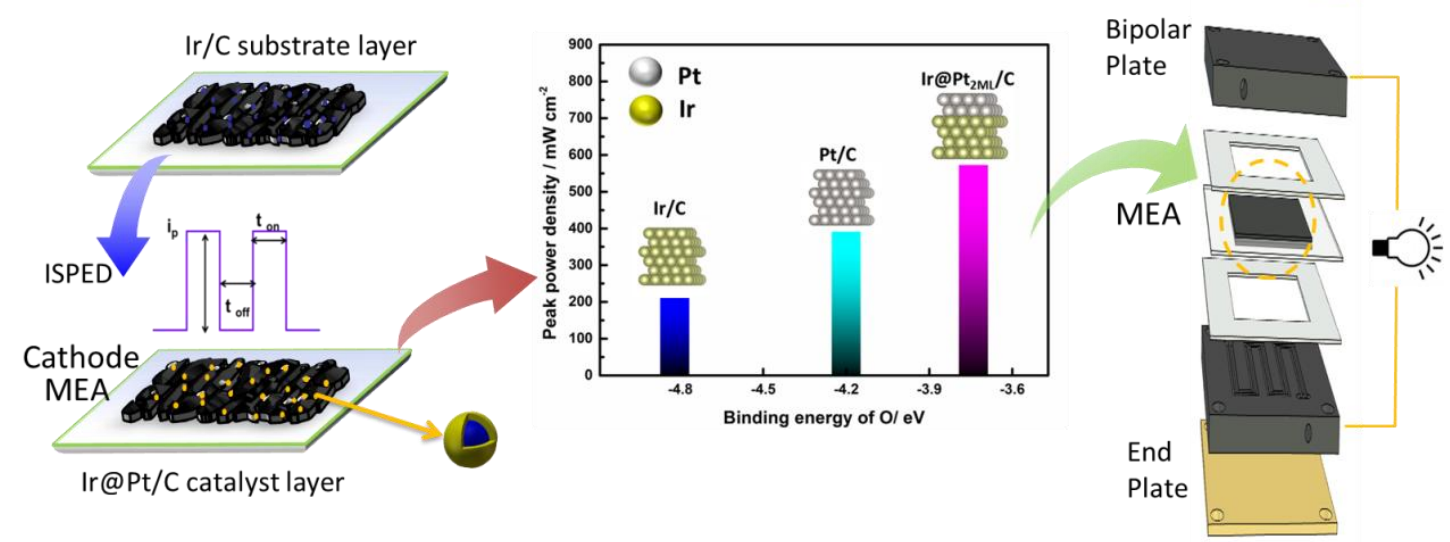